\title{
Open-label, pilot protocol of patients with rheumatoid arthritis who switch to infliximab after an incomplete response to etanercept: the opposite study
}

\author{
Daniel E Furst, Norman Gaylis, Vance Bray, Ewa Olech, David Yocum, \\ Jeffrey Ritter, Michael Weisman, Daniel J Wallace, John Crues, \\ Dinesh Khanna, Gregory Eckel, Newman Yeilding, Peter Callegari, \\ Sudha Visvanathan, Jeannie Rojas, Ronald Hegedus, Laura George, \\ Khalid Mamun, Keith Gilmer, Orrin Troum
}

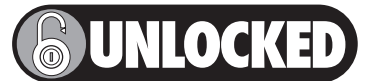

This paper is freely available online under the BMJ Journals unlocked scheme, see http://ard.bmi.com/info/unlocked.dtl
See end of article for authors' affiliations

Correspondence to: Dr D E Furst, Division of Rheumatology, Department of Medicine, University of California Los Angeles, 32-59 Rehabilitation Center 1000 Veteran Avenue, Los Angeles, CA 90095-1670, USA;

DEFursł@mednet.ucla.edu

Accepted 26 February 2007 Published Online First 5 April 2007

\begin{abstract}
Objective: To incorporate a new trial design to examine clinical response, cytokine expression and joint imaging in patients with rheumatoid arthritis (RA) switching from etanercept to infliximab treatment.

Methods: A randomised, open-label, clinical trial of 28 patients with an inadequate response to etanercept was conducted. Eligible patients received background methotrexate and were randomised 1:1 to discontinue etanercept and receive infliximab $3 \mathrm{mg} / \mathrm{kg}$ at weeks $0,2,6,14$ and 22, or to continue etanercept $25 \mathrm{mg}$ twice weekly. Data were analysed for clinical response, serum biomarker levels, radiographic progression, MRI and adverse events.

Results: At week 16, 62\% of infliximab-treated patients achieved American College of Rheumatology 20\% criteria for improvement in RA (ACR20) responses compared with $29 \%$ of etanercept-treated patients. A 30.8\% decrease from baseline in Disease Activity Score 28 was observed in patients receiving infliximab, compared with a $16.0 \%$ decrease in patients receiving etanercept. ACR2O and American College of Rheumatology $50 \%$ criteria for improvement in RA responses correlated at least minimally with intracellular adhesion molecule- 1 and interleukin 8 in patients receiving infliximab. 38\% of patients who were switched to infliximab showed reductions in Health Assessment Questionnaire scores (>0.4), compared with $0 \%$ of patients receiving etanercept. MRI analyses were inconclusive. Both drugs were well tolerated; $54 \%$ of infliximab-treated patients and $50 \%$ of etanercept-treated patients reported adverse events.

Conclusions: In this exploratory, open-label trial (with single-blind evaluator), patients were randomised to continue with etanercept or switch to infliximab. The small sample size of this hypothesis-generating study was underpowered to show statistical differences between groups. There was a numerical trend favouring patients who switched to infliximab, therefore warranting further study with a more rigorous design.
\end{abstract}

$\mathrm{T}$ he tumour necrosis factor alpha (TNF $\alpha)$ antagonist therapies, infliximab and etanercept, have revolutionised the management of inflammatory joint diseases. Both agents in combination with methotrexate (MTX) improve signs and symptoms of rheumatoid arthritis $(\mathrm{RA})^{12}$ and the joint damage caused by RA. ${ }^{13}$ Few studies have evaluated the efficacy and safety of switching infliximab and etanercept therapies to optimise patient benefit. ${ }^{5}{ }^{6}$

Clinical variability has been shown in patients' responses to treatment with anti-TNF $\alpha$ therapies. ${ }^{7-10}$ As clinical response to anti-TNF $\alpha$ therapy can vary among patients, it is not uncommon for physicians to switch a patient from one agent to another if there is an inadequate response. Studies examining therapy switches from etanercept to infliximab, ${ }^{8} 9^{11-15} 16$ or from infliximab to etanercept, ${ }^{7}{ }^{911-13}$ have been reported previously. Subanalyses based on the Stockholm TNF $\alpha$ follow-up (STURE) database ${ }^{13}$ using a cohort of patients who switched from etanercept-plus-MTX to infliximab-plus-MTX showed improved Disease Activity Score 28 (DAS28) and American College of Rheumatology (ACR)- $\mathrm{N}^{17}$ scores compared with patients who remained on a single anti-TNF $\alpha$ therapy. ${ }^{.13}$ These studies showed some beneficial effect of switching patients with inadequate responses from one anti-TNF $\alpha$ therapy to another, even though these trials were observational. This study, titled "Open-label, Pilot Protocol of patients with rheumatoid arthritis who Switch to Infliximab after an incomplete response to Etanercept" (OPPOSITE), was the first multicentre, randomised, controlled, open-label (with singleblind evaluator) study to directly compare clinical response in patients who were switched from one therapy to another. The design of this study was unique because the control group continued to receive etanercept, which allowed a direct comparison with patients receiving infliximab for the first 16 weeks. This design allowed additional analysis to be conducted for patients who did not respond to etanercept.

\section{PATIENTS AND METHODS}

Patients

Patients were eligible to participate if they were aged $\geqslant 18$ years, had a diagnosis of RA by the revised 1987 criteria

Abbreviations: ACR, American College of Rheumatology; ACR20, ACR $20 \%$ criteria for improvement in RA; ACR50, ACR 50\% criteria for improvement in RA; COL 2-3/4C long neoepitope, type II collagen cleavage by collagenase; CTX-1, C-telopeptide-1; DAS28, Disease Activity Score 28; HAQ, Health Assessment Questionnaire; ICAM-1, intracellular adhesion molecule-1; IL, interleukin; MMP-3, matrix metalloproteinase-3; MTX, methotrexate; RA, rheumatoid arthritis; SHS, Sharp score with the van der Heijde modification; SJC, swollen joint count; TJC, tender joint count; TNF $\alpha$, tumour necrosis factor alpha; VEGF, vascular endothelial growth factor 


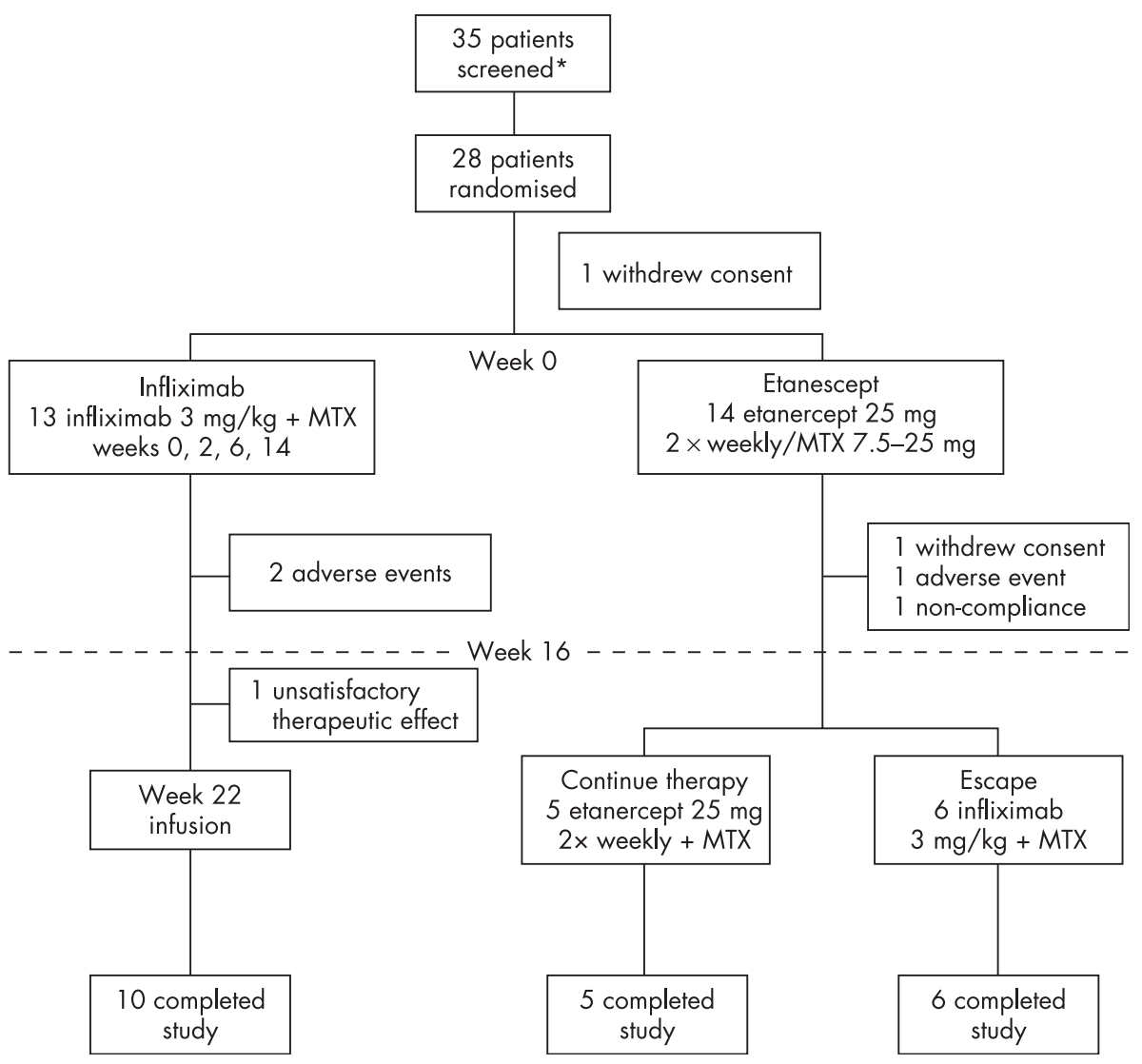

Figure 1 Patient disposition and clinical trial design diagram. MTX, methotrexate.

of the American Rheumatism Association ${ }^{18}$ and had had RA for at least 3 months. Patients were required to have received stable background MTX (7.5-25 mg/week) and a stable dose of etanercept ( $25 \mathrm{mg}$, twice weekly) for at least 2 months before entry into the study. For patients receiving corticosteroids (>10 mg prednisone), disease-modifying antirheumatic drugs or non-steroidal anti-inflammatory drugs, the dose had to be stable for 1 month before baseline. Patients were required to have a tender joint count (TJC) $\geqslant 9$ (maximum 68 ), a swollen joint count (SJC) $\geqslant 6$ (maximum 66 ), a positive rheumatoid factor and a negative purified protein derivative tuberculin skin test. Patients were required to have at least a partial response to etanercept, as manifested by improved signs and symptoms.

Patients were not eligible to participate if they had been taking anakinra within 2 months of entry into the study or had previously taken infliximab or another monoclonal antibody. Patients were excluded from the trial if they had: a rheumatic disease other than RA; a serious, chronic infectious disease within 2 months of the baseline, or opportunistic infections within 6 months; active hepatitis B; HIV; history of a malignancy (within 5 years); lymphoproliferative disorder; or any demyelinating disease.

\section{Study design}

The institutional review boards at each study centre approved the protocol. All protocol-related procedures were carried out in accordance with the principles of the Declaration of Helsinki, the International Conference of Harmonization and the United States Food and Drug Administration. All patients provided written informed consent.

A total of 28 patients were randomised at nine sites in the US. At week 0, patients were randomised in a $1: 1$ ratio to discontinue etanercept and receive infliximab $3 \mathrm{mg} / \mathrm{kg}$ or continue etanercept $25 \mathrm{mg}$ twice weekly. All patients continued to receive stable doses of MTX (7.5-25 mg) through week 30, and are hereafter referred to as patients receiving either infliximab or etanercept. Thirteen patients who discontinued etanercept received infliximab $3 \mathrm{mg} / \mathrm{kg}$ at weeks $0,2,6,14$ and 22. Fourteen patients continued etanercept $(25 \mathrm{mg})$ twice weekly for 16 weeks. Beginning at week 16, patients who were not responding to etanercept (as assessed by $\leqslant 40 \%$ improvement in TJC and SJC) were allowed to switch to infliximab at weeks 16,18 and 22.

Infliximab (Remicade, Centocor, Malvern, Pennsylvania, USA) was supplied in $20 \mathrm{ml}$ vials containing $100 \mathrm{mg}$ of lyophilised concentrate. Etanercept (Enbrel, Amgen, Thousand Oaks, California, USA) was supplied in commercially available cartons of 4-dose trays. Commercially available MTX was supplied by the doctors, and all doses were based on approved package inserts.

This study was exploratory and underpowered, but allowed for extensive evaluation of clinical outcome measures, including ACR response, ACR-N response, DAS28 response, TJC and SJC, duration of morning stiffness, patient pain, patient fatigue, global disease assessments, Beck depression index, Short Form-36 outcomes, health assessment questionnaire (HAQ) response, erythrocyte sedimentation rate, C reactive protein, analysis of inflammatory biomarkers, and analysis of radiographic progression by $x$ ray and MRI scans of the most affected hand.

An assessor who was blinded to previous and present treatment evaluated the patients for tender and swollen joints using the Sharp score with the van der Heijde modification (SHS). ${ }^{19}$ Blood samples were obtained at weeks 0, 2, 6, 10, 14 
Table 1 Baseline patient and disease characteristics

\begin{tabular}{|c|c|c|}
\hline Assessment & Infliximab & Etanercept \\
\hline Number & 13 & 14 \\
\hline Women, \% & 84.6 & 100 \\
\hline Mean (SD) age (years) & $45.1(13.5)$ & $52.2(14.5)$ \\
\hline \multicolumn{3}{|l|}{ Disease characteristics } \\
\hline \multicolumn{3}{|l|}{ Duration of disease } \\
\hline Mean (SD) (years) & $9.6(11.3)$ & $12.1(10.7)$ \\
\hline Median (years) & 4.0 & 8.7 \\
\hline Range (years) & $0.5-34.8$ & $1.7-37.0$ \\
\hline Mean (SD) SJC & $20.7(9.9)$ & $20.1(6.9)$ \\
\hline Median (years) & 18.0 & 19.5 \\
\hline Range (years) & $8.0-44.0$ & $11.0-34.0$ \\
\hline Mean (SD) TJC & 31.4 (17.7) & $25.6(14.5)$ \\
\hline Median (years) & 24.7 & 21.0 \\
\hline Range (years) & $12.0-66.0$ & $9.0-56.0$ \\
\hline \multicolumn{3}{|l|}{ CRP (mg/l) } \\
\hline Median & 2.3 & 5.9 \\
\hline Range & $0.4-50.3$ & $1.2-44.9$ \\
\hline \multicolumn{3}{|l|}{ ESR $(\mathrm{mm} / \mathrm{h})$} \\
\hline Median & 26 & 31 \\
\hline Range & $4-78$ & 7-74 \\
\hline \multicolumn{3}{|l|}{ Concomitant medications } \\
\hline Prednisone therapy, \% & 30.8 & 28.6 \\
\hline NSAID therapy, $\%$ & 69.2 & 78.6 \\
\hline DMARD therapy, \% & 100 & 100 \\
\hline \multicolumn{3}{|l|}{ Clinical assessment } \\
\hline \multicolumn{3}{|l|}{ Health Assessment } \\
\hline \multicolumn{3}{|l|}{ Questionnaire score } \\
\hline Mean (SD) & $1.4(0.7)$ & $1.5(0.6)$ \\
\hline Median (IQR) & $1.4(1.0-1.9)$ & $1.6(1.1-1.9)$ \\
\hline \multicolumn{3}{|l|}{ DAS28 score } \\
\hline Mean (SD) & $6.2(1.2)$ & $6.5(0.8)$ \\
\hline Median (IQR) & $5.9(4.2-7.7)$ & $6.5(5.2-7.6)$ \\
\hline \multicolumn{3}{|l|}{ SF-36 score } \\
\hline \multicolumn{3}{|l|}{$\begin{array}{l}\text { Physical component } \\
\text { summary }\end{array}$} \\
\hline Mean (SD) & $32.9(7.0)$ & $28.6(7.4)$ \\
\hline Median (IQR) & $30.4(29.2-39.8)$ & $27.7(24.9-31.9)$ \\
\hline \multicolumn{3}{|c|}{ Mental component summary } \\
\hline Mean (SD) & $43.8(11.2)$ & $46.2(9.9)$ \\
\hline Median (IQR) & $39.3(36.9-54.3)$ & $45.3(37.1-53.4)$ \\
\hline \multicolumn{3}{|l|}{ Beck depression inventory } \\
\hline Mean (SD) & $12.5(9.5)$ & $11.6(9.8)$ \\
\hline Median (IQR) & $8.0(5.0-23.0)$ & $9.0(5.0-14.0)$ \\
\hline \multicolumn{3}{|c|}{$\begin{array}{l}\text { Sharp score (van der Heijde } \\
\text { modified) (hands and feet) }\end{array}$} \\
\hline Mean (SD) & $32.5(39.7)$ & $47.5(50.8)$ \\
\hline Median (IQR) & $20.5(15.0-38.5)$ & $26.6(8.5-80.5)$ \\
\hline \multicolumn{3}{|c|}{$\begin{array}{l}\text { CRP, C reactive protein; DAS28, Disease Activity Score based on } 28 \text { joints; } \\
\text { DMARD, disease-modifying antirheumatic drug; ESR, erythrocyte } \\
\text { sedimentation rate; IQR, interquartile range; NSAID, non-steroidal anti- } \\
\text { inflammatory drug; SF-36, short form- } 36 \text { health survey questionnaire; SJC, } \\
\text { swollen joint count; TJC, tender joint count. }\end{array}$} \\
\hline
\end{tabular}

and 30 for analysis of complete blood count, erythrocyte sedimentation rate, $\mathrm{C}$ reactive protein, serum enzymes such as aspartate transaminase and alanine transaminase, antinuclear antibodies, and antibodies to double-stranded DNA. Radiographs of the hands, wrists and forefeet were obtained at weeks 0, 14 and 30, as were MRI scans of the second and third metacarpophalangeal joints and wrist of the most severely affected hand. MRI studies were performed using $0.2 \mathrm{~T}$ MagneVu 1000 portable MRI systems (MagneVu 1000, Carlsbad, California, USA).

\section{Laboratory analysis}

Sera were collected at weeks $0,2,6,10$ and 14 for duplicate blinded analyses of the following biomarkers: COL 2-3/4C long neoepitope (type II collagen cleavage by collagenase), Ctelopeptide-1 (CTX-1), matrix metalloproteinase-3 (MMP-3), interleukin 8 (IL8), vascular endothelial growth factor (VEGF), intracellular adhesion molecule-1 (ICAM-1) and osteocalcin. ELISA kits were used for COL 2-3/4C long neoepitope (IBEX,
Toronto, Ontario, Canada), CTX-1, osteocalcin (Nordic Biosciences, Herlev, Denmark), ICAM-1, VEGF and MMP-3 ( R \& D Systems, Minneapolis, Minnesota, USA) analyses. IL8 was analysed using a Bio-plex bead-based sandwich enzyme immunoassay technique (Bio-Rad Laboratories, Hercules, California, USA).

\section{Statistical analysis}

In this exploratory study, no formal hypothesis testing was planned, and statistical analyses were limited by the small sample size. p Values were not calculated for any baseline or clinical measures. Descriptive statistics, such as median, mean and SD, were determined for continuous variables, and counts and percentages were calculated for categorical variables. Efficacy and immunogenicity data were analysed according to the assigned treatment. Safety data were analysed according to the treatment received.

Correlations of the biomarker data with ACR 20\% criteria for improvement in RA (ACR20) response, ACR 50\% criteria for improvement in RA (ACR50) response, DAS28 score and SHS were performed using the Spearman rank correlation analysis. Analysis of biomarker levels at baseline and week 14 were performed, but only the statistically significant correlations were reported. Correlations with dichotomous variables were assigned a value of " 0 " if a response was not found, and a value of " 1 " if a response was present. No Bonferroni adjustments were made.

\section{RESULTS}

\section{Study design and characteristics of the patients}

In all, 28 patients were randomised to infliximab or etanercept therapy; one infliximab-treated patient was randomised, but not treated. The median disease duration was 9.6 years (range $0.5-34.8$ years) for infliximab-treated patients and 12.1 years (range 1.7-37.0 years) for etanercept-treated patients (tables 1 and 2, fig 1). At week 16, patients receiving etanercept either continued taking etanercept or crossed over to receive infliximab (fig 1). The disease characteristics at baseline were comparable between patients receiving infliximab and those receiving etanercept, except that patients treated with etanercept had a longer duration of RA and a higher median SHS score (26.6 vs 20.5) than patients treated with infliximab (tables 1 and 2).

\section{Clinical response}

At week 2, 30.8\% (4/13) of patients receiving infliximab achieved an ACR20 response, compared with $14.3 \%$ (2/14) of patients receiving etanercept (data not shown). Likewise, at week 16, more infliximab-treated patients achieved ACR20 and ACR50 responses than etanercept-treated patients (ACR20: $61.5 \%(8 / 13)$ and $28.6 \%$ (4/14), respectively; ACR50: $30.7 \%$ $(4 / 13)$ and $14.3 \%(2 / 14)$, respectively; table 3$)$. The median ACR-N scores at week 16, however, indicated a $28.1 \%$ improvement in patients receiving infliximab compared with $11.8 \%$ deterioration observed in patients receiving etanercept (data not shown). The DAS28 scores at week 16 supported the ACR20, ACR50 and ACR-N responses.

Patients receiving infliximab showed greater improvement in HAQ scores than those receiving etanercept. More infliximabtreated patients $(61.5 \%(8 / 13))$ achieved a clinically meaningful reduction $(>0.22)$ in the HAQ score than etanercept-treated patients (14.3\% (2/14); table 3$)$. In addition, 38.5\% (5/13) of patients receiving infliximab achieved a decrease in the HAQ score of $\geqslant 0.4$, compared with $0.0 \%$ in patients receiving etanercept (table 3).

Median baseline values for the biomarkers ICAM-1, CTX-1, IL8, osteocalcin and MMP-3 were similar across the treatment 
Table 2 Biomarker levels of patients receiving infliximab and those receiving etanercept, versus normal levels

\begin{tabular}{|c|c|c|c|}
\hline Biomarker levels & $\begin{array}{l}\text { Normal healthy } \\
\text { range }\end{array}$ & Infliximab & Etanercept \\
\hline ICAM-1 (ng/ml) & $\begin{array}{l}220.6-317.8 \\
(n=13)\end{array}$ & $342.3(153.9-867.9)$ & $382.8(200.9-707.6)$ \\
\hline CTX-1 (ng/ml) & $\begin{array}{l}0.20-1.17 \\
(n=10)\end{array}$ & $0.3(0.1-0.9)$ & $0.3(0.1-0.4)$ \\
\hline IL8 (pg/ml)* & $\begin{array}{l}\text { Unable to be } \\
\text { determined } †\end{array}$ & 35.5 (17.7-184.7) & $34.0(19.7-180.6)$ \\
\hline $\begin{array}{l}\mathrm{COL} 2-3 / 4 \mathrm{C} \text { long } \\
\text { neoepitope }(\mathrm{ng} / \mathrm{ml})\end{array}$ & $\begin{array}{l}38.4-100.5 \\
(n=15)\end{array}$ & $103.7(62.3-361.1)$ & $80.4(58.2-94.3)$ \\
\hline VEGF $(\mathrm{pg} / \mathrm{ml})$ & $\begin{array}{l}70.5-702.6 \\
(n=13)\end{array}$ & $238.6(67.3-1192)$ & $354.9(90.5-937.0)$ \\
\hline Osteocalcin (ng/ml) & $\begin{array}{l}5.9-40.3 \\
(n=12)\end{array}$ & $13.4(1.7-33.6)$ & $9.3(1.7-28.7)$ \\
\hline $\begin{array}{l}\text { Matrix metalloproteinase- } \\
3(\mathrm{ng} / \mathrm{ml})\end{array}$ & $\begin{array}{l}6.4-29.1 \\
(n=20)\end{array}$ & $19.1(4.1-170.3)$ & $17.7(6.8-68.6)$ \\
\hline \multicolumn{4}{|c|}{$\begin{array}{l}\text { COL 2-3/4 C long neoepitope, type II collagen cleavage by collagenase; CTX-1, C-telopeptide-1; ICAM-1, intracellular } \\
\text { adhesion molecule-1; IL, interleukin; VEGF, vascular endothelial growth factor. } \\
\text { *An IQR could not be determined because the majority of normal donors were below the lower limit of quantification } \\
\text { (LLOQ). } \\
\text { TThe majority of normal healthy donors had serum levels of IL8 that were below the LLOQ for the assay (15.6 pg/ml); } \\
\text { therefore, a normal range could not be determined. }\end{array}$} \\
\hline
\end{tabular}

groups. COL 2-3/4 C long neoepitope levels were lower and VEGF levels higher in etanercept-treated patients than in infliximab-treated patients (tables 1 and 2). The normal ranges in sera for the following biomarkers were used: ICAM-1, 220.6$317.8 \mathrm{ng} / \mathrm{ml}(\mathrm{n}=13)$; MMP-3, 6.4-29.1 ng/ml $(\mathrm{n}=20)$; osteocalcin, $\quad 5.9-40.3 \mathrm{ng} / \mathrm{ml} \quad(\mathrm{n}=12) ; \quad$ CTX- $1, \quad 0.20-1.17 \mathrm{ng} / \mathrm{ml}$ $(\mathrm{n}=10) ; \quad \mathrm{COL} 2-3 / 4 \mathrm{C}$ long neoepitope, $38.4-100.5 \mathrm{ng} / \mathrm{ml}$ $(\mathrm{n}=15)$; and VEGF, $70.5-702.6 \mathrm{pg} / \mathrm{ml}(\mathrm{n}=13)$. The majority of normal sera IL8 levels were below the lower limit of quantification for the assay $(15.6 \mathrm{pg} / \mathrm{ml})$; therefore, a normal range could not be determined. The sera levels of the biomarkers were within the normal range, with the exception of ICAM-1 and IL8 (table 2).

Variable changes from baseline to week 14 in levels of ICAM1, CTX-1, IL8, COL 2-3/4C long neoepitope, VEGF, osteocalcin and MMP-3 were observed in both treatment groups. At week 14 , there was very little modulation of MMP-3 in either group of patients, and all groups showed $>17 \%$ reduction in VEGF levels from baseline (data not shown).

Table 4 shows the statistically significant correlations between the per cent change in biomarker levels, and clinical and radiographic response using Spearman rank analysis. For patients receiving infliximab, the per cent change in ICAM-1

Table 3 Summary of clinical responses at week 16

\begin{tabular}{lll}
\hline Clinical end point & $\begin{array}{l}\text { Infliximab } \\
(\mathbf{n}=13)\end{array}$ & $\begin{array}{l}\text { Etanercept } \\
(\mathbf{n}=14)\end{array}$ \\
\hline $\begin{array}{c}\text { ACR20 } \\
\mathrm{n}(\%)\end{array}$ & $8(61.5 \%)$ & $4(28.6 \%)$ \\
$\begin{array}{c}\text { ACR50 } \\
\mathrm{n}(\%)\end{array}$ & $4(30.7 \%)$ & $2(14.3 \%)$ \\
$\begin{array}{c}\text { DAS28 } \\
\text { Mean (SD) } \\
\% \text { change from baseline }\end{array}$ & $\begin{array}{l}4.0(1.5) \\
\text { Patients with DAS28 score }<2.6\end{array}$ & $5.2(1.6)$ \\
$\mathrm{n}(\%)$ & $2(15.4 \%)$ & $1(7.1 \%)$ \\
$\begin{array}{c}\text { Patients with HAQ decrease }>0.22 \\
\mathrm{n}(\%)\end{array}$ & $8(61.5 \%)$ & $2(14.3 \%)$ \\
$\begin{array}{c}\text { Patients with HAQ decrease }>0.40 \\
\mathrm{n}(\%)\end{array}$ & $5(38.5 \%)$ & $0(0.0 \%)$ \\
\hline
\end{tabular}

ACR20, American College of Rheumatology 20\% improvement; ACR50, American College of Rheumatology 50\% improvement; DAS28, Disease Activity Score based on 28 joints; HAQ, Health Assessment Questionnaire. levels from baseline correlated with ACR50 responses at week $14(\mathrm{p}=0.014)$. There was also a significant correlation between the per cent change in IL8 levels and an ACR20 response at week $14(p=0.027)$. At week $14(p=0.052)$ and week 16 $(p=0.008)$, the per cent change in IL8 levels significantly correlated with an ACR50 response in infliximab-treated patients (table 4). The per cent change in osteocalcin levels correlated with a SHS response at week 14 in patients receiving infliximab $(\mathrm{p}=0.005)$.

For patients who received etanercept, significant correlations between the per cent change in biomarker levels from baseline and DAS28 scores were observed for IL8 $(p=0.041)$ and osteocalcin $(p=0.011$; table 4$)$. No significant correlations between the percent change in biomarker levels and ACR20 or ACR50 responses were observed in patients receiving etanercept (data not shown).

\section{$x$ Ray and MRI evaluation}

Overall, the changes in radiographic progression seem to be comparable between the infliximab and etanercept groups

Table 4 Statistically significant correlations of per cent change in biomarker levels from baseline, with clinical end points*

\begin{tabular}{|c|c|c|c|}
\hline Treatment & $\begin{array}{l}\text { Efficacy } \\
\text { parameter }\end{array}$ & $r$ Value & p Value \\
\hline \multicolumn{4}{|l|}{ Infliximab $(n=11)$} \\
\hline \multicolumn{4}{|l|}{ Week 14} \\
\hline ICAM-1 & ACR50 & 0.71 & 0.014 \\
\hline IL8 & ACR20 & -0.66 & 0.027 \\
\hline IL8 & ACR50 & -0.59 & 0.052 \\
\hline Osteocalcin & SHS & -0.78 & 0.004 \\
\hline \multicolumn{4}{|l|}{ Week 16} \\
\hline IL8 & ACR50 & -0.74 & 0.008 \\
\hline \multicolumn{4}{|c|}{ Etanercept $(n=12)$} \\
\hline \multicolumn{4}{|l|}{ Week 14} \\
\hline IL8 & DAS28 & -0.59 & 0.041 \\
\hline Osteocalcin & DAS28 & 0.69 & 0.011 \\
\hline
\end{tabular}

*Only statistically significant correlations are shown.

ACR20, American College of Rheumatology 20\% improvement; ACR50, American College of Rheumatology 50\% improvement; DAS28, Disease Activity Score based on 28 joints; ICAM-1, intracellular adhesion molecule1; IL8, interleukin 8; SHS, Sharp score with the van der Heijde modification. 


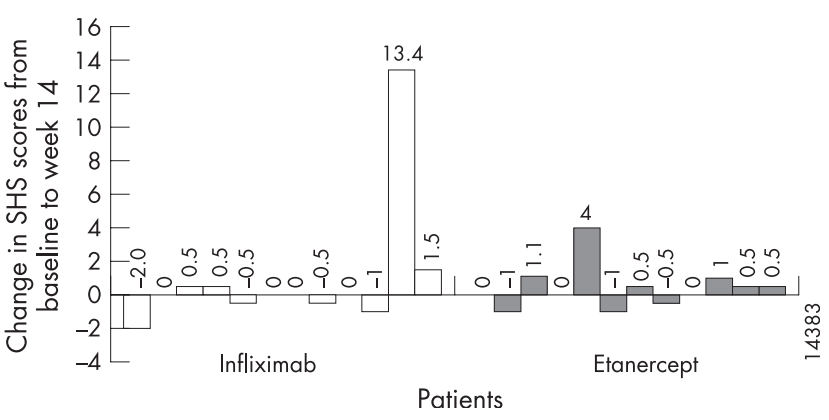

Figure 2 Change in Sharp score with the van der Heijde modification (SHS) from baseline to week 14 by patient.

(table 5). The data presented in fig 2 (the change in SHS scores by patient from baseline to week 14) may suggest a difference between the groups, with $16 \%$ more patients demonstrating an SHS score of $\leqslant 0$ in patients receiving infliximab than in those receiving etanercept. Nonetheless, caution must be exercised in interpreting these differences, because there are a lack of formal statistical comparisons, a short observation period and a limited sample size.

They were no marked differences in the median number of erosions observed with MRI between patients receiving infliximab and patients receiving etanercept. The total erosions at baseline (medians of 5.0 and 5.8, respectively) and at week 14 (medians of 5.8 and 6.0, respectively) were comparable between the treatment groups (data not shown).

\section{Safety}

The average length of treatment was 18.9 weeks for patients receiving infliximab and 11.8 weeks for patients receiving etanercept. Infliximab and etanercept were both well tolerated in this clinical trial, with a similar incidence of adverse and serious adverse events (table 6).

The most commonly occurring adverse event in all treatment groups was aggravated RA (musculoskeletal and connective tissue disorders). Nearly all adverse events were mild or moderate in intensity. Table 6 lists the adverse events that were reported in more than one patient in each of the treatment groups.

No serious adverse events were reported in more than one patient. Two patients receiving infliximab experienced serious adverse events (one patient developed urticaria, lymphadenopathy and epistaxis, and another patient developed shingles, which was considered unrelated to the study agent) and were discontinued from treatment. One patient receiving etanercept was discontinued from treatment due to congestive heart failure, unspecified cardiac neoplasm, viral infection, a cerebrovascular accident, lung infiltration and respiratory distress, which were considered unrelated to the study agent by the investigators. A total of three patients receiving infliximab experienced one or more infusion reactions, and one patient receiving etanercept experienced an injection site reaction. No instances of tuberculosis were reported in either treatment group.

\section{DISCUSSION}

This multicentre, randomised, open-label, clinical trial with single-blind evaluation of 28 patients with established RA and an incomplete response to etanercept was one of the first direct comparison trials of this kind. The design of this trial was novel because the control group continued etanercept therapy, which allowed a comparison of outcomes for patients treated with infliximab. In addition, unlike most comparative studies, there was no washout period between patients being switched from etanercept to infliximab. This uninterrupted treatment switch was possible because the presence of etanercept did not alter the pharmacokinetics of infliximab (data not shown). Further, the incorporation of biomarkers and MRI evaluations in this study allowed for the analysis of biological responses despite the open design and small numbers.

The preliminary findings in this study suggest that infliximab treatment does not attenuate the levels of MMP-3 in patients with established RA ( $\geqslant 3$ years) who are already treated with a biological agent, as compared with patients with early RA who are naive to biological agents $(<3$ years). A decrease in MMP-3 levels by infliximab was observed in an early clinical study of infliximab. ${ }^{20}$ In this small cohort of patients, MMP-3 attenuation was not shown, whereas in a population of patients with early RA, there was a significant reduction in MMP-3 levels after 6 weeks of infliximab treatment $(p=0.003){ }^{20}$ These findings support other studies in which MMP-3 levels decreased in patients with early RA following treatment with anti-TNF $\alpha$ therapies ${ }^{21}$ and disease-modifying antirheumatic drugs. ${ }^{22}$ Perhaps this difference is attributed to the fact that MMP-3 levels may already be low in patients with established

\begin{tabular}{|c|c|c|c|c|c|c|c|}
\hline \multirow[b]{2}{*}{ Evaluation } & \multirow[b]{2}{*}{ Week } & \multirow[b]{2}{*}{ n } & \multicolumn{2}{|l|}{ Infliximab } & \multirow[b]{2}{*}{$\mathrm{n}$} & \multicolumn{2}{|l|}{ Etanercept } \\
\hline & & & Mean (SD) & Median & & Mean (SD) & Median \\
\hline \multicolumn{8}{|l|}{ SHS } \\
\hline & Week 0 & 13 & $32.5(39.7)$ & 20.5 & 14 & $47.5(50.8)$ & 26.6 \\
\hline & Week 14 & 12 & $36.2(40.6)$ & 21.0 & 12 & $52.2(53.6)$ & 33.3 \\
\hline & $\begin{array}{l}{ }^{*} \text { Change from } \\
\text { week } 0 \text { to } 14\end{array}$ & 12 & $1.0(4.0)$ & 0.0 & 12 & $0.4(1.3)$ & 0.3 \\
\hline \multicolumn{8}{|c|}{ Total erosions } \\
\hline & Week 0 & 13 & $18.7(18.6)$ & 18.0 & 14 & $28.8(32.2)$ & 15.2 \\
\hline & Week 14 & 12 & 20.4 (18.5) & 18.8 & 12 & $31.3(34.0)$ & 17.8 \\
\hline & $\begin{array}{l}{ }^{*} \text { Change from } \\
\text { week } 0 \text { to } 14\end{array}$ & 12 & $0.1(0.84)$ & 0.0 & 12 & $-0.1(0.65)$ & 0.0 \\
\hline \multicolumn{8}{|l|}{ JSN } \\
\hline & Week 0 & 13 & $13.8(22.0)$ & 7.5 & 14 & $18.7(19.5)$ & 12.6 \\
\hline & Week 14 & 12 & $15.8(23.1)$ & 8.0 & 12 & $20.9(20.7)$ & 16.0 \\
\hline & $\begin{array}{l}{ }^{*} \text { Change from } \\
\text { week } 0 \text { to } 14\end{array}$ & 12 & $0.9(3.39)$ & 0.0 & 12 & $0.6(1.17)$ & 0.0 \\
\hline
\end{tabular}


Table 6 Incidence of adverse and serious adverse events

\begin{tabular}{|c|c|c|c|c|c|c|}
\hline \multirow[b]{2}{*}{ Adverse event type } & \multicolumn{3}{|c|}{ Infliximab $(n=13)$} & \multicolumn{2}{|c|}{ Etanercept continue therapy } & \multirow{2}{*}{$\begin{array}{l}\text { Escape } \\
\text { Week 16-35 } \\
(n=6)\end{array}$} \\
\hline & Week 0-15 & Week 16-35 & Week 0-35 & $\begin{array}{l}\text { Week 0-15 } \\
(n=14)\end{array}$ & $\begin{array}{l}\text { Week 0-35 } \\
(n=5)\end{array}$ & \\
\hline Serious (SAE) & $\mathrm{n}$ (\% of patients) & & & $\mathrm{n}$ (\% of patients) & & \\
\hline Patients with $\geqslant 1$ SAE & $0(0)$ & $1(7.7)$ & $1(7.7)$ & $2(14.3)$ & $1(20.0)$ & $0(0)$ \\
\hline Gastrointestinal disorders & $0(0)$ & $0(0)$ & $0(0)$ & $1(7.1)$ & $1(20.0)$ & $0(0)$ \\
\hline Cardiac disorders & $0(0)$ & $0(0)$ & $0(0)$ & $1(7.1)$ & $0(0)$ & $0(0)$ \\
\hline $\begin{array}{l}\text { Musculoskeletal and connective tissue } \\
\text { disorders }\end{array}$ & $0(0)$ & $1(7.7)$ & $1(7.7)$ & $0(0)$ & $0(0)$ & $0(0)$ \\
\hline Nervous system disorders & $0(0)$ & $0(0)$ & $0(0)$ & $1(7.1)$ & $0(0)$ & $0(0)$ \\
\hline Respiratory disorders & $0(0)$ & $0(0)$ & $0(0)$ & $1(7.1)$ & $0(0)$ & $0(0)$ \\
\hline \multicolumn{7}{|l|}{ Adverse $(\mathrm{AE})^{*}$} \\
\hline Patients with $\geqslant 1 \mathrm{AE}$ & $7(53.8)$ & $4(30.8)$ & $11(84.6)$ & $7(50.0)$ & $2(40.0)$ & $2(33.3)$ \\
\hline Gastrointestinal disorders & $0(0)$ & $0(0)$ & $0(0)$ & $3(21.4)$ & $1(20)$ & $0(0)$ \\
\hline $\begin{array}{l}\text { Musculoskeletal and connective tissue } \\
\text { disorders }\end{array}$ & $2(15.4)$ & $2(15.4)$ & $4(30.8)$ & $1(7.1)$ & $0(0)$ & $2(33.3)$ \\
\hline Nervous system disorders & $1(7.7)$ & $0(0)$ & $1(7.7)$ & $1(7.1)$ & $0(0)$ & $1(16.7)$ \\
\hline Respiratory disorders & $1(7.7)$ & $0(0)$ & $1(7.7)$ & $4(28.6)$ & $0(0)$ & $0(0)$ \\
\hline Skin and subcutaneous disorders & $3(23.1)$ & $2(15.4)$ & $5(38.5)$ & $1(7.1)$ & $0(0)$ & $0(0)$ \\
\hline General disorders and site reactions & $0(0)$ & $0(0)$ & $0(0)$ & $1(7.1)$ & $1(20.0)$ & $0(0)$ \\
\hline
\end{tabular}

RA whose levels may already be under the influence of their current biological therapy.

Although this clinical trial was small and exploratory, our results suggest that infliximab may provide additional clinical benefit for patients with an incomplete response to etanercept. Other studies have examined switching from one TNF $\alpha$ inhibitor to another, ${ }^{7-911-16}$ demonstrating that switching therapies can benefit those patients who have an inadequate response to a specific therapy; however, these studies did not include a comparative group which remained on the original therapy.

We also examined inflammatory and structural damage biomarkers, as well as correlations between biomarkers, clinical response and structural damage. Our results suggest differential regulation of inflammatory (IL8) and bone biomarkers (osteocalcin) by infliximab and etanercept, and correlations with clinical response and structural damage in patients with established RA. These data also suggest differential regulation of some biomarkers in this population compared with a population with early RA. Clinical correlations were undermined by the small sample size, making it difficult to determine whether these distinctions were because of the different modes of action of infliximab and etanercept.

This trial showed similar safety profiles for patients treated with infliximab or etanercept. These findings are similar to those of other switch trials that showed no increase in adverse events for patients who switch from infliximab to etanercept or from etanercept to infliximab. ${ }^{8} 1223$

One of the major limitations of this trial was that it was a pilot study with a single-blind design. Another limitation was the small study size, which included only 28 patients, thereby making statistical comparisons between the treatment groups tenuous. The sample size was adequate for an exploratory study, but a larger randomised double-blind trial with a longer duration of treatment would allow for better comparison between the treatment groups.

The short duration of the trial also limited the MRI evaluations and other outcome measurements in these patients. There were several factors that contributed to the inconclusive MRI findings. First, the procedure was performed over a short period of time. Second, not all hand and wrist joints were imaged. Third, the MRI equipment employed in this study had a small field of view that did not allow all joints to be fully visualised. 0.2 T MRI machines are often used in clinical settings; however, the methodology is not fully validated and did not show any differences over this very short period of time.

Because TNF $\alpha$ inhibitors have some risks associated with their administration, it is important for doctors to consider all options before switching patients from one TNF $\alpha$ inhibitor to another. The results of this trial suggest that patients who respond inadequately to one $\mathrm{TNF} \alpha$ inhibitor may respond favourably to another. The clinical response observed in this study is similar to that observed in other switching studies. ${ }^{23}$

The design of this trial can serve as a prototype for future trials involving switching from one biological agent to another. A large, double-blind direct comparison clinical trial examining a switch from one TNF $\alpha$ inhibitor to another would be of significant interest to the rheumatology community. The results of this trial provide support for the hypothesis that switching from one anti-TNF therapy to another can be of clinical benefit in some patients who fail their original therapy.

\section{ACKNOWLEDGEMENTS}

We thank Kristin Ruley, PhD, and Mary Whitman, PhD, of Centocor for their writing support; Dennis Decktor, PhD, and Greg Keenan, MD, of Centocor for their contributions to the conduct of the study and critical review of the manuscript; Sunita Bhagat and Jhilik De of Centocor for their laboratory expertise; and Gary Feldman, MD, of Pacific Arthritis Care Center, and Gary Williams, MD, of Scripps Clinic and Research Foundation for their contributions to the conduct of the study.

\section{Authors' affiliations}

Daniel E Furst, Dinesh Khanna, Division of Rheumatology, Department of Medicine, University of California Los Angeles, Los Angeles, California, USA

Norman Gaylis, Arthritis and Rheumatic Disease Specialties, Aventura, Florida, USA

Vance Bray, Denver Arthritis Clinic, Denver, Colorado, USA

Ewa Olech, Oklahoma University Health Sciences Center, Oklahoma City, Oklahoma, USA

David Yocum, University of Arizona Health Sciences Center, Tucson, Arizona, USA

Jeffrey Ritter, Center for Arthritis and Rheumatology, South Miami, Florida, USA

Michael Weisman, Cedars-Sinai Medical Center, Division of

Rheumatology, Los Angeles, California, USA

Daniel J Wallace, Wallace Rheumatic Study Center, Los Angeles,

California, USA 
John Crues, Pronet Imaging, Los Angeles, California, USA

Gregory Eckel, Department of Radiological Sciences, University of

California Los Angeles, Torrance, California, USA

Newman Yeilding, Peter Callegari, Sudha Visvanathan, Jeannie Rojas,

Ronald Hegedus, Laura George, Khalid Mamun, Keith Gilmer, Centocor, Malvern, Pennsylvania, USA

Orrin Troum, Keck School of Medicine, University of Southern California, Los Angeles, California, USA

Funding: This study was funded by Centocor, Malvern, Pennsylvania, USA.

Competing interests: DEF received grants from Amgen, Abbott, Centocor, Genentech, Roche, NIH, Novartis, Genmab and Merck, and consulting fees from Amgen, Abbott, Genentech, Roche, NIH, Novartis and Merck. NG was a consultant at the time of the study for Centocor and MagneVu. VB received grants from Amgen and Centocor. EO received grants from Amgen, Bristol-Myers Squibb, Centocor, F Hoffmann-La Roche, Genentech, Human Genome Sciences, Medlmmune, Otsuka America Pharmaceutical, speaking fees from Abbott, Centocor and MagneVu, and consulting fees from Abbott, Genentech and MagneVu. DY received grants and speaking fees from Centocor, Amgen and Abbott, and advising fees from Centocor. JR received consulting fees from Genentech and Biogenidec. MW received grants from Abbott, Actelion Pharmaceuticals, Amgen, Aspreva Pharmaceutical, BioRad Laboratories, Bristol Myers Squibb, Centocor, Genentech, Eli Lilly, Human Genome Sciences, Immunex, Immunomedics, Merck, Novartis, Pfizer, Procter and Gamble, Protein Design Labs, Sanofi Aventis, TAP Pharmaceuticals and Wyeth, and consulting fees from Abbott, Amgen, Bristol Myers, Elan Pharmaceuticals, Human Genome Sciences, Merck, Vertex Pharmaceuticals and Wyeth. DJW has no competing interests. J C owns stock in MagneVu. DK received grants from TAP Pharmaceuticals, speaking fees from Abbott, Wyeth, Amgen and Actelion Pharmaceuticals, and consulting fees from Centocor. GE has no competing interests. NY, PC, SV, JR, RH, LG, KM and KG are employees of Centocor. NY, SV, RH and LG own stock in Centocor. OT received grants, speaking fees and consulting fees from Centocor, Amgen and Wyeth.

\section{REFERENCES}

1 Lipsky PE, van der Heijde DM, St Clair EW, Furst DE, Breedveld FC, Kalden JR, for the Anti-Tumor Necrosis Factor Trial in Rheumatoid Arthritis with Concomitant Therapy Study Group, et al. Infliximab and methotrexate in the treatment of rheumatoid arthritis. N Engl J Med 2000;343:1594-602.

2 Weinblatt ME, Kremer JM, Bankhurst AD, Bulpitt KJ, Fleischmann RM, Fox RI, et al. A trial of etanercept, a recombinant tumor necrosis factor receptor: Fc fusion protein, in patients with rheumatoid arthritis receiving methotrexate. NEngl J Med 1999;340:253-9.

3 Klareskog L, van der Heijde D, de Jager JP, Gough A, Kalden J, Malaise M, for the TEMPO (Trial of Etanercept and Methotrexate with Radiographic Patient Outcomes) study investigators, et al. Therapeutic effect of the combination of etanercept and methotrexate compared with each treatment alone in patients with rheumatoid arthritis: double-blind randomised controlled trial. Lancet 2004:363:675-81

4 Maini RN, Breedveld FC, Kalden JR, Smolen JS, Furst D, Weisman MH, for the Anti-Tumor Necrosis Factor Trial in Rheumatoid Arthritis with Concomitant Therapy Study Group, et al. Sustained improvement over two years in physical function, structural damage, and signs and symptoms among patients with rheumatoid arthritis treated with infliximab and methotrexate. Arthritis Rheum 2004; $50: 1051-65$.

5 Haraoui, B. Differentiating the efficacy of the tumor necrosis factor inhibitors. Semin Arthritis Rheum 2005;34:7-11.
6 Hochberg MC, Tracy JK, Hawkins-Holt M, Flores RH. Comparison of the efficacy of the tumour necrosis factor alpha blocking agents adalimumab, etanercept, and infliximab when added to methotrexate in patients with active rheumatoid arthritis. Ann Rheum Dis 2003;62:ii13-16.

7 Favalli EG, Arreghini M, Arnoldi C, Panni B, Marchesoni A, Tosi S, et al. Antitumor necrosis factor alpha switching in rheumatoid arthritis and juvenile chronic arthritis. Arthritis Rheum 2004;51:301-2.

8 Hansen KE, Hildebrand JP, Genovese MC, Cush JJ, Patel S, Cooley DA, et al. The efficacy of switching from etanercept to infliximab in patients with rheumatoid arthritis. J Rheumatol 2004;31:1098-102.

9 van Vollenhoven RF. Switching between biological agents. Clin Exp Rheumatol 2004;22:S115-21.

10 Defilippis L, Caliri A, Anghelone S, Scibilia G, Lo Gullo R, Bagnato G. Improving outcomes in tumour necrosis factor $\alpha$ treatment: comparison of the efficacy of the tumour necrosis factor $\alpha$ blocking agents etanercept and infliximab in patients with active rheumatoid arthritis. Panminerva Med 2006:48: 129-35.

11 Brocq O, Plubel Y, Breuil V, Grisot C, Flory P, Mousnier A, et al. Etanerceptinfliximab switch in rheumatoid arthritis 14 out of 131 patients treated with anti TNF alpha. Presse Med 2002;31:1836-9.

12 Ang HT, Helfgott S. Do the clinical responses and complications following etanercept or infliximab therapy predict similar outcomes with the other fumor necrosis factor-alpha antagonists in patients with rheumatoid arthritis? J Rheumatol 2003;30:2315-18.

13 van Vollenhoven R, Harju A, Brannemark S, Klareskog L. Treatment with infliximab (Remicade) when etanercept (Enbrel) has failed or vice versa: dato from the STURE registry showing that switching tumour necrosis factor alpha blockers can make sense. Ann Rheum Dis 2003;62:1195-8.

14 Combe B. Switching between anti-TNF alpha agents: what is the evidence? Joint Bone Spine 2004;71:169-71.

15 Yazici Y, Erkan D. Do etanercept-naive patients with rheumatoid arthritis respond better to infliximab than patients for whom etanercept has failed? Ann Rheum Dis 2004;63:607-8.

16 Shergy WJ, Phillips RM Jr, Hunt RE, Hernandez J. Safety and efficacy of infliximab therapy after etanercept failure: a case series. Arthritis Rheum 2001;44:S81.

17 Bathon JM, Martin RW, Fleischmann RM, Tesser JR, Schiff MH, Keystone EC, et al. A comparison of etanercept and methotrexate in patients with early rheumatoid arthritis. N Engl J Med 2000;343:1586-93.

18 Arnett FC, Edworthy SM, Bloch DA, McShane DJ, Fries JF, Cooper NS, et al. The American Rheumatism Association 1987 revised criteria for the classification of rheumatoid arthritis. Arthritis Rheum 1988;31:315-24.

19 van der Heijde DM, van Riel PL, Nuver-Zwart IH, Gribnau FW, vad de Putte LB. Effects of hydroxychloroquine and sulphasalazine on progression of joint damage in rheumatoid arthritis. Lancet 1989;1:1036-8.

20 Visvanathan S, Smolen J, St. Clair EW, Marini JC, Pritchard C, Shergy WJ, et al. Changes in inflammatory disease markers and associations with clinical efficacy following infliximab plus methotrexate therapy in patients with early rheumatoid arthritis. Arthritis Rheum 2004;50:S396.

21 Brennan FM, Browne KA, Green PA, Jaspar JM, Maini RN, Feldman M. Reduction of serum matrix metalloproteinase 1 and matrix metalloproteinase 3 in rheumatoid arthritis patients following anti-tumor necrosis factor-?(cA2) therapy. Br J Rheumatol 1997;36:643-50.

22 Posthumus MD, Limburg PC, Westra J, van Leeuwen MA, van Riiswijk MH. Serum matrix metalloproteinase 3 levels during treatment with sulfasalazine or combination of methotrexate and sulfasalazine in patients with early rheumatoid arthritis. J Rheumatol 2002;29:883-9.

23 Hyrich KL, Lunt M, Watson KD, Symmonds DP, Silman AJ. Outcomes after switching from one anti-tumor necrosis factor alpha agent to a second anti-tumor necrosis factor alpha agent in patients with rheumatoid arthritis: results from a large UK national cohort study. Arthritis Rheum 2006;56:13-20.

24 Fleischmann RM, Cohen SB, Moreland LW, Schiff M, Mease PJ, Smith DB, et al Methotrexate dosage reduction in patients with rheumatoid arthritis beginning therapy with infliximab: the Infliximab Rheumatoid Arthritis Methotrexate Tapering (iRAMT) trial. Curr Med Res Opin 2005;21:1181-90. 